\title{
Complacent Child feeding practices versus Infant feeding practices affecting the nutritional status of Under Two children situational analysis
}

\section{Sonali Kar ${ }^{1}$, Angeleena Esther ${ }^{2}$}

${ }^{1}$ Professor, Department of Community Medicine, Kalinga Institute of Medical Sciences, Campus-5, KIIT University, Patia, Bhubaneswar, Odisha; ${ }^{2}$ Post graduate, IIIrd year, Department of Community Medicine, Kalinga Institute of Medical Sciences, Campus-5, KIIT University, Patia, Bhubaneswar, Odisha

\begin{tabular}{|c|c|c|c|c|c|c|c|}
\hline \multicolumn{2}{|c|}{\begin{tabular}{l|l} 
Abstract & Introduction \\
\end{tabular}} & Methodology & Results & Conclusion & References & Citation & Tables / Figures \\
\hline \multicolumn{8}{|c|}{ orresponding Autho } \\
\hline \multicolumn{7}{|c|}{$\begin{array}{l}\text { Dr Sonali Kar, Department of Community Medicine, Kalinga Institute of Medical Sciences, Campus-5, KIIT } \\
\text { University, Patia, Bhubaneswar, Odisha -751024 } \\
\text { E Mail ID: sonsam72@yahooco.uk }\end{array}$} & 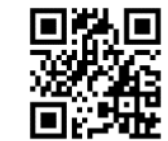 \\
\hline
\end{tabular}

\section{Citation}

Kar S, Esther A. Complacent Child feeding practices versus Infant feeding practices affecting the nutritional status of Under Two children situational analysis. Indian J Comm Health. 2020;32(1):43-50.

Source of Funding: Nil Conflict of Interest: None declared

\section{Article Cycle}

Received: 10/12/2019; Revision: 15/01/2020; Accepted: 21/02/2020; Published: 31/03/2020

This work is licensed under a Creative Commons Attribution 4.0 International License.

\section{Abstract}

Background: -To enhance child health, Indian Child Development Scheme (ICDS) and National Health Mission (NHM) strategized that reinforcement of Infant and Young Child Feeding (IYCF) practices would be a good take off. Anganwadis, where $78 \%$ of mothers of children below 6 receive services, can serve as an effective platform for mothers to receive counseling on appropriate breast feeding and complementary foods, in a priority state like Odisha. Aim: -As a prelude to a detailed intervention, a rapid baseline situational analysis was planned in 4 intervention districts to know about the district specific variations and also the overall IYCF practices in the area. Objective: Assess the IYCF indicators in the districts with focus on feeding practices above 6 months of age. Assess the factors responsible for breast feeding and complementary feeding in the sample Materials and Methods: - Final sample of 600 was chosen using 30 cluster sampling based on proportions of less than 2 years children in the study districts (districts named $A-D$, as the interventions are in progress and state refrains the identity of districts), 30 clusters to be divided in the ratio of 10:8:5:7. From each cluster-mothers of 20 children, nearly equal proportions of children in 0-6months and 7-23 months, were interviewed for sociodemographic, health seeking and prevailing IYCF practices. BMI (Body Mass Index) and MUAC (Mid Upper arm Circumference) were used to corroborate the nutritional status of child. Results: - 606 interviews were conducted. Age groups ratio was 2:1.5. Exclusive breast feeding was noted at $68 \%$ and under nutrition was $59.2 \%$. Advanced maternal age were positively associated with declining breast-feeding practice; however good spacing and male child was protective for good IYCF practices. The complementary feeding practices, measured with 2 major indicators i.e. Minimum Food Diversity and Minimum Meal Frequency, were calculated as $40.7 \%$ and $20.6 \%$ respectively. Gender representation for both indicators was positively skewed for females, which was reasoned in FGDs as purely by chance and did not mean a preference for boys. Both service provider and the mothers' knowledge was compromised regarding complementary feeding indicators, in spite of the fact that former had been trained on this aspect. Conclusion: - Targeted interventions are envisaged as scope for improvement in the IYCF indicators in the mixed mileu of a state, wherein some districts indicators markedly affect the overall state indicators. In Odisha, this study may give guidelines to the intervening districts to overhaul the load of under nutrition which is now more district and select population specific.

\section{Keywords}

IYCF; Minimum Meal Frequency; Minimum Food Diversity, Complementary Feeding

\section{Introduction}

Odisha known to be one of the low performing states of India with an Infant Mortality Rate of 51/1,000 live births against the national average of 40. (SRS 2013). Neonatal
Mortality Rate (NMR) has reduced from 53 (SRS 2005) to 37 (SRS 2013) keeping pace with decline in IMR.(1) The state is committed to improve its health indicators, given a favorable political and programmatic environment. Administrative units are districts and the District Health 
Surveys (DHS) which are done annually give a fair picture of the health status of the districts. The DHS 2013 for Odisha has shown that the districts with tribal and vulnerable population have scored poorly in case of child health indicators. These populations have their firm cultural practices and are resistant to outer influences. The WHO and UNICEF have developed the Global Strategy for Infant and Young Child Feeding (IYCF), recognizing appropriate infant feeding practices to be crucial for improving nutrition status and decreasing infant mortality in all countries. (2)

Most studies conducted in India have focused on mainly the breastfeeding practices and not the dietary diversity and diet frequency aspects, which are important in IYCF. The present study envisaged to conduct a rapid assessment of IYCF practices, the stakeholder's contribution as well as to identify gaps in the community level that are impeding the IYCF practices in priority areas.

\section{Aims \& Objectives}

1. To assess the IYCF indicators in the districts

2. To find the association of IYCF indicators (as a whole) against the demographic and social variables

\section{Material \& Methods}

Study area: -The study was initiated after due state approval in 4 major interventional districts of Odisha, which were selected due their performances in state health indicators and for the purpose of the article are named as $A$ to $D$. The main stakeholders of the study were CINI, UNICEF and State of Odisha.

Sample size calculation: -The sample size was built up, on reports of minimum dietary diversity and minimum acceptable diet among 6-23 months children reported as 67.4 and 80.3 as per a Delhi study in 2012 (3). On the basis of reported prevalence of minimum dietary diversity was $67.4 \%$, at two-sided $95 \%$ confidence interval, and $10 \%$ relative error in the reported prevalence, calculated sample size came out to be 186 . Using design effect of 2 , revised calculated sample is 372 . Assuming $10 \%$ nonresponse rate, minimum targeted sample size is $410.0 n$ the basis of the other reported prevalence of minimum acceptable diet was $80.3 \%$, at two-sided $95 \%$ confidence interval, and $6 \%$ relative error in the reported prevalence, calculated sample size came out to be 262 . Using design effect of 2 and $10 \%$ non-response rate, minimum required targeted sample size was 576. Finally, in this study, sample size was taken 600. Sample size was calculated using power analysis and sample size, version-2008 (PASS8).

Study type and method: -To draw the sample size of 600 from the four districts, 30 cluster sampling technique (using multistage cluster sampling) was adopted. First from each district, two blocks were selected randomly (first stage).From the selected block, all the village / wards were considered equally important and out of them, assigned number of clusters (villages/wards) were selected (second stage).According to the proportion of the children in the proposed study age group, 30 clusters were divided in the ratio of $10(A): 8(B): 7(C): 5(D)$ as per the population proportion sampling (PPS). From each of the selected cluster, 20 children were selected using purposive sampling with an attempt to choose proportionate number of boys and girls and 10 children in 0-6 months of age and 10 children from 11-23 months of age. In case of the 20 children were not achieved in a particular cluster (village/ward), nearest cluster was used to select the remaining children. If children from any gender are not there, then they were replaced by the ones that are available and same for the age sub groups also.

The block selection was carried out in discussion with the District and ICDS officials keeping in mind the child indicators of 2017 like IMR, the percentage of malnourished children and antenatal care delivery indicators in the block. Study duration: -Feasibility in terms of accessibility of the households was also kept in mind, this being a fast track project and thus data collection was completed in fifteen days time.

Study population: - Households bearing children aged 023 months were the primary sampling units which were sampled eventually randomly from the village lists available as per the population in the villages. The exercise was planned the week prior to the survey, by contacting the concerned district and block officials.

Inclusion and exclusion: -

Data collection methods: -Data collection was initiated in the entire 4 districts simultaneously with a team of 3 field data collectors, 1 immediate supervisor and some subcentre (SC) level ground staff to enable facilitation. The timeline for data collection was 15 days.

A facilitation meeting was taken up at the selected block level, prior to the data collection to help in the house listing of the selected clusters and also have a primary contact with the ground level workers to seek their help in the data collection activity. This also helped to sensitize them on the ensuing FGD (Focus Group Discussion) by the team supervisor during the course of the household survey.

For assessment of contribution of stakeholders, available staff (ANM, ASHA, AWW and ICDS supervisor) from each of the selected clusters were approached during the FGD during the Sector meetings/VHND days, to discuss the gaps in IYCF practices and counseling thereof, in the area, against a pretested checklist.

The data tool was essentially a questionnaire that was developed, adapted from the pretested tools of Propane study 2015 and USAID WHO tool for IYCF practices 2010. The tool had sections on:

- Socio-demographic details

- Obstetric, antenatal care and delivery details

- Early breast feeding patterns (for 0-5 months age)

- Complimentary feeding patterns (6-23months age)

- Knowledge of mother's on IYCF practices 
- Knowledge of ground health workers on IYCF practices

- Anthropometric details of the child

Ethical consideration: -

The study was a part of bigger joint initiative of UNICEF Odisha and CINI of bettering IYCF practices in four chosen districts and had the ethical clearance of the state and district level authorities. Bilingual version of the study tool was developed for local usage and pilot tested for suitability, local acceptability and appropriateness.

Data analysis: -The collated data in sheets was entered in excel and rechecked by team at KIMS and finally analyzed and inferred by using SPSS Statistics for Windows, version 15.0 (SPSS Inc., Chicago, III., USA.) Data analysis was attempted mostly in percentages for categorical variables and as means for continuous variables. Chi-square was used for statistical significance at $95 \% \mathrm{Cl}$, at values less than 0.5 for categorical data.

Descriptive statistics of the study variables are detailed in the results section.

\section{Operational Derivatives in the study:}

The IYCF indicators derived in the study are calculated in 2 distinct age groups i.e. 0-5 months of age and the other one being 6-23 months of age for ease of addressable at the policy level and also to match the exclusive breastfeeding recommendations.

The data and statistics on Infant Young Child Feeding are heavily dependent on the respondents i.e. the mothers in community surveys and selection of the right universes for sample selection. The detailed lists of the IYCF indicators taken up in this study are:

- Early initiation of breastfeeding: Proportion of children born in the last 24 months who were put to the breast within one hour of birth.

- Exclusive Breastfeeding under 6 months: Proportion of infants 0-6 months of age who are fed exclusively with breast milk.

- Continued Breastfeeding at 1 year: Proportion of children 12-15 months of age who are fed breast milk.

- Minimum Dietary or Food Diversity: Definition: Proportion of children 6-23 months of age who receive foods from 4 or more food groups.

- Calculation of $\mathbf{7}$ food group score: The 7 foods groups used for calculation of this indicator are

- grains

- pulses and legumes

- roots and tubers

- dairy products (milk, yogurt, cheese)

- flesh foods (meat, fish, poultry and liver/organ meats) and eggs

- vegetables and leafy vegetables and fruits

- Nuts and oilseeds

- Minimum Meal Frequency: Proportion of breastfed and non-breastfed children 6-23 months of age who receive solid, semi-solid, or soft foods (but also including milk feeds for non-breastfed children) the minimum number of times or more
The accepted GOI IYCF guidelines for calculation of this indicator are by actual measure of feeds given at specified age groups. An age stratified recommendation exits regarding the minimum feed that the infant should receive till 2 years of age. The same tool was used to calculate minimum meal frequency in this rapid survey. The table was given as a part of the questionnaire and any deviations from the minimum recommendations was noted as the parameter being violated. The table used is listed below:

Ideal feeding practices of respective age groups (Minimum Meal Frequency calculation)

\begin{tabular}{|c|c|}
\hline Age groups & Ideal feeding practice \\
\hline 0-6 months & Only breast milk \\
\hline 6-7 months & $\begin{array}{l}\text { 2-3 spoons of extra feeds twice a day and } \\
\text { predominantly breast feed }\end{array}$ \\
\hline 7-8 months & $\begin{array}{l}2-3 \text { times/d of half standard feeding cup of } \\
250 \mathrm{ml} \text {; and } 1 \text { additional snack }\end{array}$ \\
\hline 9-11 months & $\begin{array}{l}3 \text { main meals; feed } 1 / 2 \text { to } 3 / 4 \text { the cup and } 1-2 \\
\text { additional snack }\end{array}$ \\
\hline 12-23months & $\begin{array}{l}3 \text { main meals } 3 / 4 \text { to } 1-1 \frac{1}{4} \text { cup per feed; } 1-2 \\
\text { additional snack }\end{array}$ \\
\hline
\end{tabular}

The field exercise was used as an opportunity to do an immediate anthropometry check of the children of the consenting mothers. Weight, height and mid arm circumference were measured by the field supervisors. For weight, the use of Salter's scale at the AWW was encouraged and measurement noted to the nearest $0.1 \mathrm{~kg}$ after zero correction (4).For length the team was provided with length boards and the child was laid supine on a plain surface and the length was taken in the presence of the mother and a helper (who would help hold the knees and the head of the child in such a way that the child lay in a straight line) and is measured to the nearest millimeter (5). MUAC was noted using the Shakir's UNICEF tape as per the latest recommendations for children aged above 6 months (6).

\section{Results}

A total of 606 children were taken up in the study in the age group 0-23 months of age; wherein the age group break up was 189 children in 0-5 months of age and 417 in 6-23 months of age. The F:M proportion achieved was 4.5:5.5. (Table 1)

(Table 2A) depicts the IYCF practices in the sampled districts (may not be considered as the district specific samples are not representative of whole district) and total sample too. The NFHS -4 survey (2015-2016) gives data for only 2 of the indicators which are exclusive breast feeding and early initiation of breast feeding. Dramatic improvement is seen in the 2 parameters with both showing a nearly $20 \%$ rise in the practices overall, taking the cumulative figures to above $80 \%$ for both indices against the 60\% above figures reported in NFHS 4 . However, in districts like $D$ there is a decline of practice of EBF and B registers no improvement. The study also showed that practice of prelacteal feeds had declined a 
mere $13 \%$ in total sample. Thus, the results for breast feeding indicators looked very promising in all districts.

The food groups as described in the methodology are seven in number and for the sake of analysis, we have stratified the groups into 1-2 groups, 3 groups and 4 and above groups of food taken by the child. This indicator is calculated only for 6-23 months of age children. The ideal and acceptable is 4 and above food groups and in the aggregate analysis we see that $20.6 \%$ of the whole sample had the recommended combination of 4 and more food groups and another nearly $20 \%$ only 3 food groups. Practice of consuming 1-2 food groups in this age group was highest in all 4 districts. Hence major intervention, thrust and reinforcement is needed in enhancing the indicator of food diversity in the sample as a whole. The very low figures in the increasing food groups disabled to carry out detailed sub stratified analysis between further age group subdivisions and also regarding consumption of iron rich and Vitamin A rich foods across the sampled districts. The main food groups that were consumed crosssectionally in all districts were cereals and pulses along with milk. (Table 2B)

Food diversity is not very different for either gender. Better diversity is seen in case of girls though the difference is not very significant. Males are seen consuming more 1-2 food groups. This was seen from qualitative reports that males are fed and cared for primarily by the mothers and hence is breast fed for longer periods and consume homemade cereals alone. Females cope better to home conditions and start eating from different caregivers, and hence the food diversity is better in their case. (Table 3 )

As indicated in the (Table 4) the indicator of Minimum Meal Frequency varied from $78.79 \%$ in $D$ to $45.45 \%$ in $B$ district. The aggregate is $62.46 \%$ in the given sample. This is calculated as a proportion of total responses meeting the minimum meal frequency standards out of the total sample in the district. This needs different levels and strategies of reinforcement in different districts. This indicator is the core to stunting and hence needs to be addressed sensitively. The ICDS scheme provides graduated jars/katoras of fixed volume capacity for measurement of uncooked and that of served food for the children in 6-23 months of age. However, it has come out in the survey that these tools are treated with great laxity both on part of the home caregiver i.e. the mother or guardian and the health care giver. No monitoring or recapitulation of the mother's knowledge and practice in this area is done and there is heavy preponderance of cultural practices like the child not allowed to feed complete home meals till 2 years of age and is put primarily on a milk-based diet.

(Figure 1) shows that minimum meal frequency does not have any significant variations gender wise. Females fair marginally better i.e. $65 \%$ as compared to boys i.e. $60.3 \%$.
The reasons are the same, where ironically the lapse of too much attention in case of the girl child and also her ability often to self-feed is seen as a reason why girls have better meal frequency than the boys. Good education programs inculcating importance of meal frequency both for the ground level workers as well as community dissemination on VHNDs would be a good way to push this indicator.

An attempt to derive some significant socio demographic parameters was done using Chi square test for the given sample for early initiation of breast feeding and it emerged that only place of delivery bore a strong association $(p=0.035)$ in this sample wherein the practice needs reinforcement in home and private hospitals. All other variables like mother's ascending age, caste, gender or LBW showed no statistically significant difference between the practice and those who could not initiate it. (Table 5)

Similar analysis for EBF did not bring out any significant determining variable as overall the practices were good in the sample as a whole or were neglected because of strong cultural bias.

(Table 6): Shows a similar analysis for food diversity wherein more socio demographic factors showed significance. The place of delivery continued to emerge statistically significant wherein poor diversity was noted in children born in private hospitals, which could be because lack of counseling in these facilities for IYCF and also the parents seek services from these service providers only during delivery and cease to seek help afterwards. The frontline workers too perhaps do not give adequate focus to this group and thus special focus is to be offered to these mothers including those going in for home delivery. Here age of the mother too showed a highly significant association with food diversity in feeding $(p=0.003)$ with the indicator being worst at 59\% not giving 4 and more food groups at age till 20 years and the figures improving with age. This could be because the very young mothers or maybe prime are entrusted with more household work and have less time to offer to the young one and another could be their resistance and immaturity to the counselling given, which could explain why the practice improves with age. Thus, at the time of intervention more focus to be given to this age group of mothers.

Similarly, those mothers with knowledge on EBF had poor complementary feeding indicators which prove that complementary feeding counseling is not appropriately and adequately done at most centers. The stagnancy of knowledge that breast feeding is good enough for the child, often hits the complementary feeding practices, which has come out very strongly in our analysis that the mother's as well as the health provider's knowledge and focus on complementary feeding practices is not diligent enough. 
Interestingly, mothers who fetch water offered better food diversity (0.007) to their children, which could be because of the peer effect and scope of discussion amidst each other. So here a positive trend of availability of water within household is proving disadvantageous for the mothers who become home bound and loose the benefit of getting exposure to knowledge dissemination. This also would need further in-depth qualitative analysis during the midline evaluation.

The weight for height was normal in $79 \%$, showing that stunting is improving, though severe malnutrition (weight for age ) was noted for $23.2 \%$ and severe height for age in $19 \%$, though corroborative MUAC was not in <-3 z-score scale for that many, suggesting that the anthropometric findings would have to be reconfirmed. Hence further analysis on this was not attempted.

\section{Discussion}

The early breast feeding indicators are well reported in this study in the sample overall, which shows marked improvement of an analysis done for NFHS 2005-2006 national data (7) wherein only $23 \%$ initiated breast feeding(EBIF) in one hour (which has improved to $87 \%$ in current study), 99.2\% had ever breastfed their infant, $89.8 \%$ were currently breastfeeding, and $14.8 \%$ were currently bottle-feeding (all these rates being similar to our study findings). The rates of timely initiation of breastfeeding were higher among women who were better educated (OR for secondary education or above $=$ $0.79)$, were working $(O R=0.79)$, made more antenatal clinic visits (OR for $\geq 7$ antenatal visits $=0.48$ ), and were exposed to the radio $(O R=0.76)$. In this study, only delivery at an institution (be it public or private) affected early EIBF $(p=0.035)$. Since the data was taken from very marginalized and underserved populations, no significance was judged for education or age of the mothers as most of the mothers were just literate or within 20 years of age. The rates of timely complementary feeding were higher for mothers who had more antenatal visits $(O R=0.57)$, and for those who watched television $(\mathrm{OR}=0.75)$ in the NFHS 4 data (7) but in our study age of the mother showed a highly significant association with food diversity in feeding $(p=0.003)$ with the indicator being worst at $59 \%$ not giving 4 and more food groups at age till 20 years and the figures improving with age. This could be because the very young mothers or maybe those pregnant for first time are entrusted with more household work and have less time to offer to the young one and another could be their resistance and immaturity to the counseling given, which could explain why the practice improves with age. Thus, at the time of intervention more focus to be given to this age group of mothers. Lack of counseling is reinforced by the fact that those who knew about EBF, reported poor knowledge on food diversity. Food diversity was reported in only $20.6 \%$ in whole sample, is close to dismal figures reported in West Bengal
(8) wherein appropriate feeding as per the IMNCI protocol was significantly less among infants aged 6-11 months (15.2\%) and children aged $12-23$ months (8.7\%). The lack of food diversity needs to contemplated by the district level officials as the study shows that most children took mix of cereals and pulses, while it could not be elicited from the mothers regarding the use of the fortified flour and eggs that are provided to this age group under the ICDS scheme which hints at traditional barriers and misconceptions against use of public services as hinted in a study in Zimbabwe (9) . The anthropometric measurements had some missing data and hence were not taken up in the analysis as this study was done fast track and soon the behavioral and educational interventions were planned. The IYCF data is however discussed to generate awareness among both health providers as well as consumers, regarding the intricate gaps in our IYCF system and how it needs sincere targeted interventions sometimes at the regional and local level for overhauling.

\section{Conclusion}

This study provides relevant data on breast feeding practices with inter district variations. Targeted interventions can be planned with regards to individual districts.

\section{Recommendation}

Knowledge of the frontline workers, on whom the IYCF dissemination depends heavily needs up gradation from time to time especially with regards to complementary feeding. The continuum of care approach has to be applied here and the principles of breast feeding and infant feeding should be introduced to the mothers right from pregnancy and repeated triggers offered till the child is 2 years of age. Growth monitoring and nutritional assessment has come put as an extremely weak link as far as frontline workers are concerned. Capacity building in this area in the form of supportive supervision is essential.

\section{Limitation of the study}

The study offers a rapid baseline assessment and brings out some priority areas of interventions. However, it needs to be supported by a qualitative midline assessment to be able to compliment the targeted interventions and give better and sustainable outputs.

\section{Relevance of the study}

This data would serve as a baseline for project outcomes and evaluation against midline and endline surveys. It would also help the functionaries of the participating districts as well the stakeholders i.e. CINI and UNICEF in planning and dissemination of the project

\section{Authors Contribution}

The corresponding author did the primary data analysis and compilation of the study results and supporting 
INDIAN JOURNAL OF COMMUNITY HEALTH / VOL 32 / ISSUE NO 01 / JAN - MAR 2020 author helped in data entry, cleaning and in other accessory requirements

\section{Acknowledgement}

The team acknowledges the joint venture of UNICEF Odisha, Nutrition Division and $\mathrm{CINI}$, in particular $\mathrm{Mr}$. Sourav Bhattacharjee (Nutrition Specialist, UNICEF, Odisha) and Mrs. Prajna Chowdhury (UNICEF consultant) Mr. Swapan Bikash Saha, Project Director Nutrition (CINI) for assigning the task of data management and analysis of the data. All district and block level staff who handheld for data collection and team of data collectors are also acknowledged for their contribution. Dr. Parthibane is also thanked for his support for cross checking some of the detailed statistical analysis done for the study.

\section{References}

1. Sample Registration System (SRS ... - 2011 Census of India.http://censusindia.gov.in/vital_statistics/SRS_Bulletins/Bulle tins.html (accessed April 9, 2020).

2. Global Strategy for Infant and Young Child Feeding UNICEF.https://www.unicef.org/nutrition/files/Global_Strategy_I nfant_and_Young_Child_Feeding.pdf (accessed April 9, 2020).

3. Khan AM, Kayina P, Agrawal P, Gupta A, Kannan AT. A study on infant and young child feeding practices among mothers attending
[Complacent Child...] | Kar S et al an urban health center in East Delhi.Indian journal of public health. 2012 Oct 1;56(4):301.

4. UNICEF, 1986, How to weigh and measure children: assessing the nutrition status of young children.

5. UNICEF, 1986, How to weigh and measure children: assessing the nutrition status of young children

6. de On is M, Onyango AW, Borghi E, Garza C, Yang $\mathrm{H}$ for the WHO Multicentre Growth Reference Study Group. Comparison of the World Health Organization (WHO) Child Growth Standards and the National Center for Health Statistics/WHO international growth reference: implications for child health programmes. Public Health Nutrition, 2006, 9:942-7

7. Patel A, Badhoniya N, Khadse S, Senarath U, Agho KE, Dibley MJ, South Asia Infant Feeding Research Network (SAIFRN)*. Infant and young child feeding indicators and determinants of poor feeding practices in India: secondary data analysis of National Family Health Survey 2005-06. Food and nutrition bulletin. 2010 Jun;31(2):31433.

8. Sinhababu A, Mukhopadhyay DK, Panja TK, Saren AB, Mandal NK, Biswas $A B$. Infant-and young child-feeding practices in Bankura district, West Bengal, India. Journal of health, population, and nutrition. 2010 Jun;28(3):294.

9. Paul K.H., Muti M., Chasekwa B., Mbuya M.N., Rufaro M.C., Humphrey J.H. et al. (2010) Complementary feeding messages that target cultural barriers enhance both the use of lipid-based nutrient supplements and underlying feeding practices to improve infant diets in rural Zimbabwe. Maternal and Child Nutrition 8, 11740- 18709

\section{Tables}

\begin{tabular}{|c|c|c|c|c|c|c|c|}
\hline \multirow{2}{*}{$\begin{array}{l}\text { District } \\
30 \\
\text { clusters } \\
\text { PPS }\end{array}$} & \multirow{2}{*}{$\begin{array}{c}\text { Target } \\
\text { Clusters per } \\
\text { district (expected } \\
\text { sample) }\end{array}$} & \multirow{2}{*}{$\begin{array}{l}\text { Actual } \\
\text { sample } \\
(\%)\end{array}$} & \multicolumn{2}{|c|}{$\begin{array}{l}\text { Age group wise } \\
\text { (column \%) }\end{array}$} & \multicolumn{3}{|c|}{ Gender } \\
\hline & & & $0-5$ mths & $6-23 m$ ths & $F$ & $M$ & $\begin{array}{l}\text { Non } \\
\text { response }\end{array}$ \\
\hline A & $10(200)$ & $200(33.0)$ & $56(29.6 \%)$ & $144(34.5 \%)$ & 88 (32.6\%) & 112 (34.4\%) & - \\
\hline B & $8(160)$ & $162(26.7)$ & $60(31.7 \%)$ & $102(24.5 \%)$ & $74(27.4 \%)$ & $86(26.4 \%)$ & 2 \\
\hline C & $7(140)$ & $143(23.6)$ & $41(21.7 \%)$ & $102(24.5 \%)$ & $60(22.2 \%)$ & $75(23.0 \%)$ & 8 \\
\hline D & $5(100)$ & 101(16.7) & $32(16.9 \%)$ & 69 (16.5\%) & $48(17.8 \%)$ & $53(16.3 \%)$ & - \\
\hline $\begin{array}{c}\text { Total } \\
\text { sample }\end{array}$ & 600 & 606 & 189 & 417 & $270(44.6)$ & 326 (53.8) & $10(1.7)$ \\
\hline
\end{tabular}

TABLE 2A IYCF INDICATORS- A. BREAST FEEDING PRACTICES

\begin{tabular}{|c|c|c|c|c|c|}
\hline \multirow[t]{2}{*}{ Variables } & \multicolumn{5}{|c|}{ Frequency (\% calculated as per the indices definition) } \\
\hline & $A(n=200)$ & $B(n=162)$ & $C(n=143)$ & $D(n=101)$ & Total \\
\hline Early initiation of breast feeding & $181(90.5)$ & $143(92.3)$ & 134(93.7) & $70(69.3)$ & $528(87.1)$ \\
\hline NFHS -4 & 56.8 & 71 & 62 & 70.7 & 68.6 \\
\hline Exclusive breast feeding (denominator is $0-5$ & $56(100)$ & $42(70)$ & $41(100)$ & $16(50)$ & $155(82.01)$ \\
\hline months aged infants) NFHS -4 & 62.5 & 70.2 & 71.7 & 70.2 & 65.6 \\
\hline Continued breast feeding up to 1 year & $28(100.0)$ & $29(100.0)$ & $26(100.0)$ & $11(100.0)$ & $94(100.0)$ \\
\hline Children ever breast fed & $199(99.5)$ & $153(98.7)$ & $143(100.0)$ & $101(100.0)$ & $596(99.5)$ \\
\hline Continued breast fed at 2 years & $18(85.7)$ & $5(100.0)$ & $21(91.3)$ & $16(100.0)$ & $60(91.3)$ \\
\hline Bottle feeding & $23(28.4)$ & $7(9.2)$ & $4(4.4)$ & $58(66.7)$ & $92(15.2)$ \\
\hline
\end{tabular}

\section{TABLE 2B FOOD DIVERSITY IN 6-23 MONTHS AGE GROUPS IN SAMPLE}

\begin{tabular}{|l|c|c|c|}
\hline & Food Groups & Total Count (417) & Total (100\%) \\
\hline 1-2 food groups & 248 & 59.5 \\
\hline 3 food groups & \& more food groups & 83 & 19.9 \\
\hline
\end{tabular}




\section{TABLE 3 DIVERSITY OF FOOD (GENDER WISE)}

\begin{tabular}{|c|c|c|c|}
\hline \multirow[t]{2}{*}{ Food diversity } & \multicolumn{3}{|c|}{ Gender } \\
\hline & Female & Male & No response \\
\hline \multirow[t]{2}{*}{ 1-2 food groups } & 108 & 138 & 2 \\
\hline & $58.7 \%$ & $61.4 \%$ & $25.0 \%$ \\
\hline \multirow[t]{2}{*}{3 food groups } & 31 & 50 & 2 \\
\hline & $16.8 \%$ & $22.2 \%$ & $25.0 \%$ \\
\hline \multirow[t]{2}{*}{4 and more food groups } & 45 & 37 & 4 \\
\hline & $24.5 \%$ & $16.4 \%$ & $50.0 \%$ \\
\hline Total (\%) & $184(100 \%)$ & 225 (100\%) & $8(100 \%)$ \\
\hline
\end{tabular}

\section{TABLE 4 MINIMUM MEAL FREQUENCY IN DISTRICTS SAMPLE}

\begin{tabular}{|l|c|c|c|c|c|}
\hline \multicolumn{1}{|c|}{ Minimum Meal frequency } & A & B & D \\
\hline Yes & 86 & 25 & 71 & 26 \\
\hline No & 57 & 30 & 31 & 7 \\
\hline Total responses & 143 & 55 & 102 & 33 \\
\hline$\quad$ Percentage (calculated as those reported yes/total responses) & $\mathbf{6 0 . 1 3 \%}$ & $\mathbf{4 5 . 4 5 \%}$ & $\mathbf{6 9 . 6 \%}$ & $\mathbf{7 8 . 7 9 \%}$ & $\mathbf{6 2 . 4 6 \%}$ \\
\hline
\end{tabular}

\begin{tabular}{|c|c|c|c|}
\hline Variables & Early initiated BF f (\%) & Not initiated BF f (\%) & $p$ value \\
\hline \multicolumn{4}{|l|}{ Birth weight } \\
\hline Low birth weight & $114(89.1)$ & $14(10.9)$ & \multirow[t]{2}{*}{0.571} \\
\hline Normal birth weight & $381(87.2)$ & $56(12.8)$ & \\
\hline \multicolumn{4}{|l|}{ Child sex } \\
\hline Male & $284(88.5)$ & $37(11.5)$ & \multirow[t]{2}{*}{0.769} \\
\hline Female & $235(87.7)$ & $33(12.3)$ & \\
\hline \multicolumn{4}{|l|}{ Child birth place } \\
\hline At home & $30(81.1)$ & $7(18.9)$ & \multirow[t]{3}{*}{0.035} \\
\hline BPHC and Government facility & $323(90.5)$ & $34(9.5)$ & \\
\hline Private Hospital & $155(83.8)$ & $30(16.2)$ & \\
\hline \multicolumn{4}{|l|}{ Mothers age } \\
\hline Up to 20 years & $77(89.5)$ & $9(10.5)$ & \multirow[t]{3}{*}{0.371} \\
\hline 21-30years & $404(88.4)$ & $53(11.6)$ & \\
\hline More than 30 years & $41(82.0)$ & $9(18.0)$ & \\
\hline \multicolumn{4}{|l|}{ Caste } \\
\hline General & $27(77.1)$ & $8(22.9)$ & \multirow[t]{4}{*}{0.164} \\
\hline OBC & $145(88.4)$ & 19 (11.6) & \\
\hline SC & $89(86.4)$ & $14(13.6)$ & \\
\hline ST & $264(89.8)$ & $30(10.2)$ & \\
\hline
\end{tabular}

\section{TABLE 6 FACTORS INFLUENCING MINIMUM DIETARY DIVERSITY FOR 6 TO 23 MONTH CHILD}

\begin{tabular}{|c|c|c|c|}
\hline Variables & Not provided f (\%) & Provided $f(\%)$ & p value \\
\hline \multicolumn{4}{|l|}{ Birth weight } \\
\hline Low birth weight & $52(56.5)$ & $40(43.5)$ & \multirow[t]{2}{*}{0.696} \\
\hline Normal birth weight & $187(58.8)$ & $131(41.2)$ & \\
\hline \multicolumn{4}{|l|}{ Child sex } \\
\hline Male & $142(61.5)$ & $89(38.5)$ & \multirow[t]{2}{*}{0.493} \\
\hline Female & $107(58.2)$ & $77(41.8)$ & \\
\hline \multicolumn{4}{|l|}{ Child birth place } \\
\hline At home & $18(66.7)$ & $9(33.3)$ & \multirow[t]{3}{*}{0.054} \\
\hline BPHC\& Govt facility & $162(62.3)$ & $98(37.7)$ & \\
\hline Private Hospital & $66(50.4)$ & $65(49.6)$ & \\
\hline \multicolumn{4}{|l|}{ Mothers age } \\
\hline Up to 20 years & $25(41.0)$ & $36(59.0)$ & \multirow[t]{3}{*}{0.003} \\
\hline 21-30years & 192(62.0) & $122(38.0)$ & \\
\hline More than $\mathbf{3 0}$ years & $26(72.0)$ & $10(27.8)$ & \\
\hline
\end{tabular}




\begin{tabular}{|c|c|c|c|}
\hline General & $8(40.0)$ & $12(60.0)$ & \multirow[t]{4}{*}{0.153} \\
\hline OBC & $83(65.4)$ & $44(34.6)$ & \\
\hline SC & $38(56.7)$ & $29(43.3)$ & \\
\hline ST & $121(58.5)$ & $171(40.6)$ & \\
\hline \multicolumn{4}{|l|}{ Religion } \\
\hline Hindu & $239(59.6)$ & $162(40.4)$ & \multirow[t]{2}{*}{0.683} \\
\hline Christian & $11(55.0)$ & $9(45.0)$ & \\
\hline \multicolumn{4}{|l|}{ Knowledge on EBF duration } \\
\hline Correct response & $162(53.6)$ & $140(46.4)$ & \multirow[t]{2}{*}{$<0.001$} \\
\hline Wrong response & $66(75.0)$ & $22(25.0)$ & \\
\hline \multicolumn{4}{|c|}{ Travel distance for fetching drinking water } \\
\hline Within household & $50(66.7)$ & $25(33.3)$ & \multirow[t]{5}{*}{0.007} \\
\hline Less than 5 minutes & $116(51.9 \%)$ & $108(48.2)$ & \\
\hline 5-15 minutes & $64(67.4)$ & $31(32.6)$ & \\
\hline $15-30$ minutes & $18(75)$ & $6(25.0)$ & \\
\hline More than $\mathbf{3 0}$ minutes & $3(100.0)$ & $0(0.0)$ & \\
\hline
\end{tabular}

\section{Figures}

FIGURE 1 MIN MEAL FREQUENCY -GENDER VARIATIONS

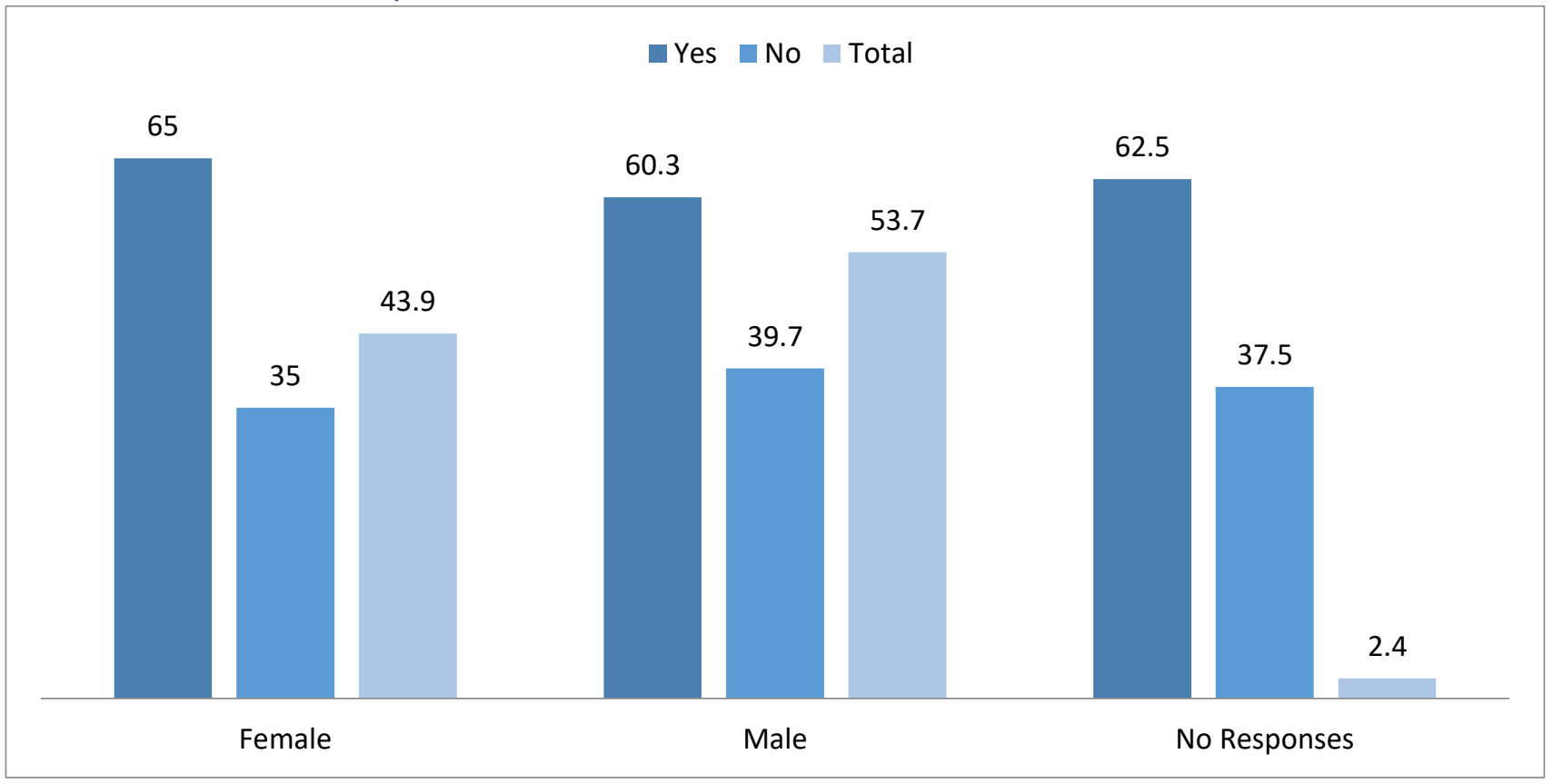

